\title{
Universiteit
}

Leiden

The Netherlands

\section{Incidence of venous thrombosis in a large cohort of 66329 cancer patients: results of a record linkage study}

Blom, J.W.; Vanderschoot, J.P.M.; Oostindier, M.J.; Osanto, S.; Meer, F.J.M. van der;

Rosendaal, F.R.

\section{Citation}

Blom, J. W., Vanderschoot, J. P. M., Oostindier, M. J., Osanto, S., Meer, F. J. M. van der, \& Rosendaal, F. R. (2006). Incidence of venous thrombosis in a large cohort of 66329 cancer patients: results of a record linkage study. Journal Of Thrombosis And Haemostasis, 4(3), 529-535. Retrieved from https://hdl.handle.net/1887/5022

Version: $\quad$ Not Applicable (or Unknown)

License:

Downloaded from: https://hdl.handle.net/1887/5022

Note: To cite this publication please use the final published version (if applicable). 


\title{
Incidence of venous thrombosis in a large cohort of 66329 cancer patients: results of a record linkage study
}

\author{
J.W. BLOM, ${ }^{*}$ J.P. M. VANDERSCHOOT,†M. J. OOSTINDIËR, $\$$ S. OSANTO, \& F. J. M. VAN DER MEER, \\ and F. R. ROSENDAAL* \\ *Department of Clinical Epidemiology, Leiden University Medical Center, Leiden; †Department of Medical Informatics, Leiden University \\ Medical Center, Leiden; $¥$ Comprehensive Cancer Center, Leiden; §Department of Oncology, Leiden University Medical Center, Leiden; \\ $\checkmark$ Hemostasis and Thrombosis Research Center, Leiden University Medical Center, Leiden, the Netherlands
}

To cite this article: Blom JW, Vanderschoot JPM, Oostindiër MJ, Osanto S, van der Meer FJM, Rosendaal FR. Incidence of venous thrombosis in a large cohort of 66329 cancer patients: results of a record linkage study. J Thromb Haemost 2006; 4: 529-35.

See also H. T. Sørensen. Cancer and subsequent risk of venous thromboembolism. This issue, pp 527-8.

Summary. Background: The incidence of venous thrombosis (VT) for cancer patients is increased compared with patients without cancer, but estimations of the incidence for different types of cancer have rarely been made because of the low incidence of various types of cancer. Large registries offer an opportunity to study the risk of VT in large cohorts of cancer patients, which is essential in decisions on prophylactic anti-coagulant treatment. Methods: This cohort study estimates the incidence of VT in cancer patients by using record linkage of a Cancer Registry and an Anticoagulation Clinic database in the Netherlands. Cumulative incidences in patients with different types of malignancies were estimated. We calculated relative risks (RRs) in relation to the presence of distant metastases and treatment. Results: Tumors of the bone, ovary, brain, and pancreas are associated with the highest incidence of VT (37.7, 32.6, 32.1, and 22.7/1000/0.5 year). Patients with distant metastases had a 1.9-fold increased risk $\left[\mathrm{RR}_{\mathrm{adj}}\right.$ : 1.9 ; 95\% confidence interval (CI): 1.6-2.3]. Chemotherapy leads to a 2.2-fold increased risk $\left(\mathrm{RR}_{\mathrm{adj}}: 2.2 ; 95 \% \mathrm{CI}\right.$ : 1.8-2.7) and hormonal therapy leads to a 1.6-fold increased risk $\left(\mathrm{RR}_{\text {adj }}: 1.6 ; 95 \% \mathrm{CI}: 1.3-2.1\right)$ compared with patients not using these treatment modalities. Patients with radiotherapy or surgery did not have an increased risk. Conclusions: We compared the overall incidences of VT in the first half year in our study to the risk of major bleeding as described in the literature. For patients with distant metastases, for several types of cancer, prophylactic anti-thrombotic treatment could be beneficial.

Correspondence: F. R. Rosendaal, Department of Clinical Epidemiology, C9-P, Leiden University Medical Center, PO Box 9600, 2300 RC Leiden, the Netherlands.

E-mail f.r.rosendaal@lumc.nl

Received 21 August 2005, accepted 16 November 2005
Keywords: deep vein thrombosis, incidence, malignancy.

\section{Introduction}

Patients with cancer have an increased risk of deep vein thrombosis (DVT) compared with patients without cancer [1,2]. This increased risk varies between different types of cancer [2-4]. In a recent case-control study, the highest risk was associated with lung cancer [odds ratio (OR): $22.2 ; 95 \%$ confidence interval (CI): 3.6-136.1], hematological cancer (OR: 28.0; 95\% CI: 4.0-199.7), and gastrointestinal cancer (OR: 20.3; 95\% CI: 4.9-83.0) [2]. Cancers with a moderately increased risk were ovarian cancer (OR: 3.1; 95\% CI: 0.6-15.3) and prostate cancer (OR: 2.2; 95\% CI: 0.9-5.4). Because of a relatively low incidence of various types of cancer, large cohort studies are needed to accurately estimate the incidence of venous thrombosis (VT) in cancer with a low incidence. For clinical practice, knowledge of the incidence of VT in cancer patients is helpful with regard to making decisions about prophylactic antithrombotic treatment.

Database linkage has been proved to be a powerful tool in epidemiological studies concerning the incidence of cancer after VT. Two Scandinavian studies linked cohorts of patients with VT defined from National Registries of Patients with data from National Cancer Registries [5,6]. Likewise, large cohorts of different types of malignancy can be defined from large databases, and consequently be linked to databases with information about VT incidence. An American study using a Medicare database estimated the incidence of VT in cancer patients in the first 6 months after cancer diagnosis, by linking hospital discharge data from different periods [7]. Tumors of the ovary, brain, and pancreas had the strongest association with VT in the Scandinavian studies as well as the American study. Although database linkage is very effective, the reliability of the results is dependent on the quality of the registers used. The health event has to lead to registration and details such as diagnosis or identifying variables have to be recorded correctly. 
The following cohort study is based on patient records from the Cancer Registry in the mid-western part of the Netherlands, an urbanized area around the cities of Leiden and The Hague. Linkage with the database of two Anticoagulation Clinics in the same area is performed with the aim to find incident symptomatic cases of DVT. After performing a validation study of the linkage procedure, we estimated the incidence of DVT in patients with different types of malignancies before as well as after the cancer diagnosis. Additionally, we studied the effect of distant metastases, surgery, chemotherapy, and radiotherapy on the risk.

\section{Methods}

The study cohort was defined as the incident cancer cases from 1986 to December 2002 entered in the populationbased Cancer Registry of the Comprehensive Cancer Center West in the western part of the Netherlands, Leiden. This Cancer Registry is one of the nine Dutch regional cancer registries and covers $10 \%$ of the Dutch population (approximately 1.6 million people). It has been operating since 1986. Tumor data are abstracted from pathology reports and medical records of hospital admissions. From 1989 the coverage is more than 98\% [8]. From the Cancer Registry we obtained demographic data of the patients, information about the type of tumor, date of tumor diagnosis, and type of initial therapy. We selected patients from 1986 to December 2002 who were living in the catchment area of the anticoagulation clinics of Leiden and The Hague at the time of cancer diagnosis. Records of these patients were linked to the database of the anticoagulation clinics of The Hague and Leiden. In the Netherlands, anticoagulation clinics manage the outpatient oral anticoagulation treatment of all patients in a well-defined geographical area. The data from the anticoagulation clinics of Leiden and The Hague were used to define the incidence of DVT in the cohort of cancer patients registered in the Cancer Registry. From the Anticoagulation Clinic database we used demographic data, indication for anticoagulant therapy, and start and end date of anticoagulant therapy.

\section{Validation study}

To determine the optimal linkage procedure, we randomly selected records of patients with and without cancer from the anticoagulation clinic in Leiden. These patients underwent anticoagulant therapy during the period 1990-1994. As a rule but not consistently, a diagnosis of cancer is reported by patients or their physicians to the anticoagulation clinics and consequently registered in its database. Therefore, we could select 166 patients who had cancer registered in the records of the Anticoagulation Clinic. We also selected 456 patients without cancer from the database of the anticoagulation clinics. These 456 patients were also enrolled in the Multiple Environmental and Genetic Assessment of risk factors for venous thrombosis study (MEGA study) and had reported absence of cancer [2]. Subsequently, we performed a record linkage with the database of the Cancer Registry.

Personal identifying variables registered by the Cancer Registry are first four letters of the family name, first initial, birth date, sex, and postal code. These identifiers were also available from the anticoagulation clinics. The variables used for the record linkage were the first four letters of the family name and the birth date. The variables sex, first initial, and postal code were used for additional visual evaluation of the links (i.e. records linking together). We evaluated all links with equal birth date and equal first four letters of the family name with a systematic procedure using the identifiers' sex, first initial, and postal code to improve the specificity of our linkage procedure. Small differences in either first initial or postal code were accepted as a match. A difference in sex was accepted in case all other variables were equal or in case there was either a minor difference in the postal code or a difference in first initial.

In this validation, we used the data from the anticoagulation clinics as standard, and calculated the sensitivity of linkage as those registered with thrombosis and without cancer in the anticoagulation clinics, who were linked as positive for cancer in the Cancer Registry, and as specificity the patients with thrombosis and without cancer according to the anticoagulation clinics, who were not found in the Cancer Registry. Our rationale for this approach was that the anticoagulation clinics' registry is based on medical treatment which is absolutely required for $\mathrm{VT}$, that we could obtain positive information on the absence of cancer from an independent study, and that another approach would have been difficult to reconcile without knowing the level of co-morbidity in the cancer patients from the Cancer Registry.

\section{Linkage of complete databases}

After validating our linkage procedure, we performed a linkage of the complete databases of the Cancer Registry $(n=86151$ patients) and the anticoagulation clinics ( $n=157482$ patients), and calculated incidences of DVT 1 year before cancer diagnosis and after cancer diagnosis per tumor type. Information about use of anticoagulation therapy for other reasons than VT was not used in the analyses.

\section{Statistical analysis}

In the absence of mortality data (the Cancer Registry includes data only from the time of diagnosis and treatment) we calculated the cumulative incidence over the first 6 months since cancer diagnosis as a measure of risk, in order to compare between different types of cancer. In addition, the cumulative incidence of VT since cancer diagnosis using the median survival time per type of cancer was calculated. Median survival time was obtained from the Eindhoven Cancer Registry, comprising an area in the south of The Netherlands [9]. The cumulative incidence is calculated as the proportion of patients who developed VT in the specified time period after the 
cancer diagnosis. The denominator is the number of patients at the start of the study.

To compare the effect of different forms of therapy, we estimated relative risks (RRs) with $95 \%$ confidence intervals (CI). The risk of developing VT in the first half year after cancer diagnosis for patients undergoing chemotherapy, radiotherapy, hormonal therapy or surgery as initial therapy, was compared with the risk for patients without these treatment modalities. Estimates of RRs are adjusted for possible confounders, such as age and sex, by using MantelHaenszel methods.

Among the cancer patients with a VT event in the 6 months after cancer diagnosis, we estimated the cumulative incidence of a recurrence in the six months after the thrombotic event and compared it with the cumulative incidence in the 6th to 12th month for patients without a thrombotic event in the first 6 months by calculating an RR.

The analysis of incidence of VT in the presence of distant metastases was performed in a subgroup of patients for whom the absence or presence of distant metastases was known $(n=$ 38739 of a total of 66329 patients). Calculations of incidences were made with the STATA.8 software package.

\section{Results}

\section{Validation study}

All links with identical date of birth and identical first four letters of the family name were reported. After visual inspection of the other identifiers, all reported links were accepted as matches as the other identifiers were also identical in the reported links. Ten records out of 166 cancer patients could not be matched. This yielded a sensitivity of $94.0 \%$. Three of the 10 records of patients with cancer which could not find a match in the Cancer Registry were those of patients who came to live in the area of the Comprehensive Cancer Center West after their cancer diagnosis and were thus not registered. Three other records did not find a match in the Cancer Registry because of the lack of complete coverage of the Cancer Registry. One patient was registered with a different birth date in the anticoagulation clinic database than in the Cancer Registry but other identifiers were identical. Three other patients had an identical birth date in both registries but spelling differences in the name. Four of 456 records of patients without cancer found a match in the Cancer Registry. These four matches were falsepositive links. Linkage occurred because of errors in the spelling of the name or birth date. We calculated a specificity of $99.1 \%$. Using additional evaluation of the other identifiers (sex, first initial, and postal code) in the validation set showed an increase in specificity to $99.8 \%$, and no decrease in sensitivity.

\section{Linkage study}

The linkage procedure was performed with the complete databases, that is, not only patients with VT but also all patients from the anticoagulation clinic were included. In total,
86151 patients with cancer were registered in the Cancer Registry database and 73358 (Leiden) and 84124 (The Hague) patients in the database of the anticoagulation clinics. We found 17095 persons with a link. All positive links were evaluated by comparing the identifiers - sex, initials, and postal code. We decided $3.6 \%$ of positive links not to be a match.

In the anticoagulation clinic of Leiden, before 1990, the indication code for anticoagulant therapy was removed from the database when the patient received a new, different indication. As a consequence, of 17095 persons with a link $937(5.5 \%)$ missed an indication for the therapy in the earlier years. For the analysis, only matches with VT were included.

\section{Incidence of VT}

A total of 66329 patients with a first, single tumor between 1986 and 2002 were included in the analysis. There were 33253 women $(50.1 \%)$ and 33076 men (49.9\%). We found 2149 patients with a VT in the year before the diagnosis of cancer or after the diagnosis of cancer: 1240 patients with DVT of the leg, 127 patients with DVT of the arm, 696 patients with a pulmonary embolism (PE), and 86 patients with other forms of VT (VT in a rare location, such as portal vein or mesenterial vein, or location not registered). A recurrent VT event was found in 270 patients and three patients had a third event.

Patients without a VT had a median age of 66.6 years $(25$ th75th percentile: 56.7-75.3) and patients with VT had a median age of 68.5 (25th-75th percentile: 56.9-77.3). There were more women among the patients with VT $(52.0 \%)$ than among those without VT $(50.1 \%)$.

The overall cumulative incidence of VT in the first 6 months was $12.3 / 1000$ patients with cancer $(95 \% \mathrm{CI}$ : 11.5-13.0). Patients with tumors of the bone, ovary, brain, and pancreas had the highest cumulative incidence of DVT of the leg or arm or PE in the first half year after diagnosis of cancer (Table 1). The risk of a VT within 6 months after this first thrombotic event was 18.4/1000/0.5 year (11.1-30.0), 4.6-fold increased $\left(\mathrm{RR}_{\mathrm{adj}}\right.$ : 4.6; 95\% CI: 2.6-7.8) compared with cancer patients who did not have a thrombotic event in the 6 months after cancer diagnosis (3.9/1000/0.5 year; 95\% CI: 3.44 .4$)$. Recurrences were most often seen in patients with leukemia $(11 / 22)$, brain cancer $(3 / 34)$ and cancer of the bladder, ureter $(2 / 29)$, and testis $(1 / 5)$. There was no difference for patients with or without distant metastases (RR adj: 0.6; 95\% CI: 0.2-2.5).

Patients with tumors of the ovary and pancreas also had a high cumulative incidence of DVT in the year before the cancer diagnosis. As the median survival time differs depending on tumor type, cumulative incidences were also calculated per median survival by tumor type (Table 2).

Overall, the incidence in the first half year after cancer diagnosis in patients with distant metastases was two times higher $\left(\mathrm{RR}_{\mathrm{adj}}\right.$ : 1.9; 95\% CI: 1.6-2.3) than in patients without distant metastases $(20.5 / 1000 / 0.5$ year; 95\% CI: 
Table 1 Cumulative incidence of venous thrombosis by tumor type, with or without distant metastases, in first 6 months after cancer diagnosis, 1 year before cancer diagnosis and recurrent venous thrombosis

\begin{tabular}{|c|c|c|c|c|c|c|}
\hline $\begin{array}{l}\text { Type of } \\
\text { malignancy }\end{array}$ & $\begin{array}{l}\text { No. of } \\
\text { patients }\end{array}$ & $\begin{array}{l}\text { No. of VTE } \\
\text { first } 0.5 \text { year }\end{array}$ & $\begin{array}{l}\text { Cumulative } \\
\text { incidence per } \\
1000 \text { patients } \\
(95 \% \mathrm{CI})\end{array}$ & $\begin{array}{l}\text { Cumulative incidence } \\
\text { per } 1000 \text { patients with } \\
\text { distant metastases } \\
(95 \% \mathrm{CI})\end{array}$ & $\begin{array}{l}\text { No. of VTE } \\
\text { in year before } \\
\text { cancer }\end{array}$ & $\begin{array}{l}\text { Cumulative } \\
\text { incidence in year } \\
\text { before cancer per } \\
1000 \text { patients }(95 \% \mathrm{CI})\end{array}$ \\
\hline Melanoma & 2236 & 6 & $2.7(1.2-6.0)$ & - & 3 & $1.3(0.43-4.15)$ \\
\hline Liver, bile ducts & 970 & 7 & $7.2(3.4-15.1)$ & $7.9(1.1-53.7)$ & 5 & $5.2(2.2-12.3)$ \\
\hline Breast & 10566 & 84 & $8.0(6.4-9.8)$ & $24.8(14.8-41.5)$ & 15 & $1.4(0.9-2.4)$ \\
\hline Rectum, anus & 2024 & 18 & $8.9(5.6-14.1)$ & $12.4(4.0-37.6)$ & 6 & $3.0(1.3-6.6)$ \\
\hline Prostate & 6013 & 57 & $9.5(7.3-12.3)$ & $14.0(8.6-22.7)$ & 19 & $3.2(2.0-5.0)$ \\
\hline Testis & 480 & 5 & $10.4(4.3(24.8)$ & $40.8(10.2-149.1)$ & 0 & - \\
\hline Uterus & 1431 & 15 & $10.5(6.3-17.3)$ & $79.0(25.7-218.0)$ & 6 & $4.2(1.9-9.3)$ \\
\hline Multiple myeloma & 900 & 10 & $11.1(6.0-20.5)$ & - & 0 & - \\
\hline Esophagus & 1040 & 13 & $12.5(7.3-21.4)$ & $16.7(6.3-43.6)$ & 2 & $1.9(0.5-7.7)$ \\
\hline Kidney & 1503 & 19 & $12.6(8.1-19.7)$ & - & 5 & $3.3(1.4-8.0)$ \\
\hline Bladder + ureter & 2250 & 29 & $12.9(9.0-18.5)$ & $30.6(9.9-90.6)$ & 9 & $4.0(2.1-7.7)$ \\
\hline Colon & 6262 & 84 & $13.4(10.8-16.6)$ & $19.3(12.5-29.7)$ & 25 & $4.0(2.7-5.9)$ \\
\hline Leukemia & 1594 & 22 & $13.8(9.1-20.9)$ & - & 6 & $3.8(1.7-8.4)$ \\
\hline ALL & 168 & 2 & $11.9(3.0-46.3)$ & - & 1 & $6.0(0.8-41.0)$ \\
\hline CLL & 524 & 9 & $17.2(9.0-32.7)$ & - & 2 & $3.8(1.0-15.1)$ \\
\hline ANLL & 532 & 9 & $16.9(8.8-32.2)$ & - & 1 & $1.9(0.3-13.2)$ \\
\hline CML & 165 & 1 & $6.1(0.9-41.7)$ & - & 0 & - \\
\hline Other leukemias & 205 & 1 & $4.9(0.7-33.8)$ & - & 2 & $9.8(2.4-38.2)$ \\
\hline Lung & 9336 & 129 & $13.8(11.6-16.4)$ & $17.9(13.6-23.5)$ & 39 & $4.2(3.1-5.7)$ \\
\hline Stomach & 2337 & 36 & $15.4(11.1-21.3)$ & $10.5(5.0-21.9)$ & 12 & $5.1(2.9-9.0)$ \\
\hline Cervix uteri & 866 & 14 & $16.2(9.6-27.1)$ & $34.5(4.8-207.9)$ & 1 & $1.2(0.2-8.2)$ \\
\hline Hodgkin's lymphoma & 417 & 7 & $16.8(8.0-34.8)$ & - & 0 & - \\
\hline $\begin{array}{l}\text { Non-Hodgkin's } \\
\text { lymphoma }\end{array}$ & 2470 & 49 & $19.8(15.0-26.2)$ & - & 5 & $2.0(0.8-4.9)$ \\
\hline Pancreas & 1674 & 38 & $22.7(16.6-31.0)$ & $51.6(34.5-76.4)$ & 10 & $6.0(3.2-11.1)$ \\
\hline Brain & 1058 & 34 & $32.1(23.1-44.6)$ & - & 1 & $1.0(0.13-6.7)$ \\
\hline Ovary & 1444 & 47 & $32.6(24.5-43.1)$ & $49.8(27.0-90.0)$ & 13 & $9.0(5.2-15.4)$ \\
\hline Bone & 159 & 6 & $37.7(17.1-81.4)$ & $62.5(8.7-335.4)$ & 0 & - \\
\hline Other & 9299 & 86 & & & & \\
\hline Total & 66329 & 815 & $12.3(11.5-13.0)$ & & & \\
\hline
\end{tabular}

VTE, venous thrombotic event; ALL, acute lymphocytic leukemia; CLL, chronic lymphocytic leukemia; ANLL, acute non-lymphocytic leukemia; CML, chronic myeloid leukemia.

17.7-23.8 and 10.9/1000/0.5 year; 95\% CI: 9.8-12.1, respectively).

\section{Risk associated with therapy}

Patients who underwent chemotherapy as initial treatment had an increased risk of VT. This effect was slightly stronger for patients with distant metastases $\left(\mathrm{RR}_{\text {adj }}\right.$ : 2.4, 95\% CI: $1.7-3.3$ vs. $\mathrm{RR}_{\text {adj: }}$ 2.0, 95\% CI: 1.6-2.6) (Table 3). The overall RR for chemotherapy adjusted for distant metastases, was $2.2\left(\mathrm{RR}_{\mathrm{adj}}\right.$ 2.2, 95\% CI: 1.8-2.7), compared with that for patients who never underwent chemotherapy. There was no increased risk for patients undergoing radiotherapy $\left(\mathrm{RR}_{\mathrm{adj}}\right.$ : 0.7; 95\% CI: $0.6-$ 0.9 , compared with patients who did not undergo radiotherapy) or surgery $\left(\mathrm{RR}_{\mathrm{adj}} 1.0 ; 95 \% \mathrm{CI}\right.$ : $0.8-1.2$, compared to patients who did not have surgery) as initial treatment. The same analyses while adjusting treatment modalities for each other did not alter the RRs. Hormone therapy for breast cancer patients was associated with 1.8-fold increased risk for patients without distant metastases and a 1.3-fold increased risk for patients with distant metastases (Table 3) (overall $\mathrm{RR}_{\mathrm{adj}}$ : 1.6; 95\% CI: 1.3-2.1). The risk associated with hormone treatment in men with prostate cancer was only slightly increased (Table 3) ( $\mathrm{RR}_{\text {adj: }}$ 1.2; 95\% CI: 0.8-1.7) and independent from the presence of distant metastases.

\section{Discussion}

For all types of malignancies combined, this cohort of 66329 patients with cancer has a risk of VT of 12.3 per 1000 over the first 6 months after diagnosis (annualized: 24.6 per 1000 per year), which is clearly higher than the thrombosis risk in the population (2 per 1000 per year) [10]. Patients with tumors of the bone, ovary, brain, and pancreas had the highest incidence of VT [6,7] (37.7, 32.6, 32.1, and 22.7/1000/ 0.5 year, respectively). Patients with distant metastases and those undergoing chemotherapy had a 2-fold increased risk compared with those without metastases or not using chemotherapy. Hormonal therapy led to a 1.5-fold increased risk in breast cancer patients but not in prostate cancer patients. For patients with radiotherapy or surgery, the risk was not increased.

Patients who had their first thrombosis within 6 months after cancer diagnosis had a 4.8 -fold increased risk of VT in the 
Table 2 Incidence of venous thrombosis per type of malignancy during median survival time

\begin{tabular}{|c|c|c|c|c|}
\hline Type of malignancy & $\begin{array}{l}\text { No. of } \\
\text { patients }\end{array}$ & $\begin{array}{l}\text { Median survival } \\
\text { (months) }\end{array}$ & $\begin{array}{l}\text { No. of VTE in } \\
\text { median survival time }\end{array}$ & $\begin{array}{l}\text { Cumulative incidence } \\
\text { per } 1000 \text { patients }(95 \% \mathrm{CI})\end{array}$ \\
\hline Melanoma & 2236 & 47.5 & 19 & $8.5(5.4-13.3)$ \\
\hline Liver, bile ducts & 970 & 2 & 2 & $2.1(0.5-8.2)$ \\
\hline Breast & 10566 & 129 & 371 & $35.1(31.8-38.8)$ \\
\hline Rectum, anus & 2024 & 45 & 41 & $20.3(15.0-27.4)$ \\
\hline Prostate & 6013 & 42 & 168 & $27.9(24.1-32.4)$ \\
\hline Testis & 480 & 289 & 9 & $18.8(9.8-35.6)$ \\
\hline Uterus & 1431 & 189 & 55 & $38.4(29.6-49.7)$ \\
\hline Multiple myeloma & 900 & 28 & 20 & $22.2(14.4-34.2)$ \\
\hline Esophagus & 1040 & 8 & 16 & $15.4(9.5-25.0)$ \\
\hline Kidney & 1503 & 39 & 36 & $24.0(17.3-33.0)$ \\
\hline Bladder + ureter & 2250 & 33 & 61 & $27.1(21.2-34.7)$ \\
\hline Colon & 6262 & 40 & 148 & $23.6(20.2-27.7)$ \\
\hline Leukemia & 1594 & - & - & - \\
\hline ALL & 168 & 11 & 2 & $11.9(3.0-46.3)$ \\
\hline CLL & 524 & 53 & 16 & $30.5(18.8-49.3)$ \\
\hline ANLL & 532 & 5 & 9 & $16.9(8.8-32.2)$ \\
\hline CML & 165 & 31 & 3 & $18.2(5.9-54.8)$ \\
\hline Other leukemias & 205 & 14 & 4 & $19.5(7.3-50.8)$ \\
\hline Lung & 9336 & 8 & 152 & $16.3(13.9-19.1)$ \\
\hline Stomach & 2337 & 8.5 & 40 & $17.1(12.6-23.3)$ \\
\hline Cervix uteri & 866 & 99 & 27 & $31.2(21.5-45.1)$ \\
\hline Hodgkin's lymphoma & 417 & 220 & 15 & $36.0(21.8-58.8)$ \\
\hline Non-Hodgkin's lymphoma & 2470 & 35 & 71 & $28.7(22.8-36.1)$ \\
\hline Pancreas & 1674 & 4 & 33 & $19.7(14.1-27.6)$ \\
\hline Brain & 1058 & 6 & 34 & $32.1(23.1-44.6)$ \\
\hline Ovary & 1444 & 30 & 65 & $45.0(35.5-57.0)$ \\
\hline Bone & 159 & 67 & 9 & $56.6(29.7-105.2)$ \\
\hline Other & 9299 & & & \\
\hline Total & 66329 & & & \\
\hline
\end{tabular}

VTE, venous thrombotic event; ALL, acute lymphocytic leukemia; CLL, chronic lymphocytic leukemia; ANLL, acute non-lymphocytic leukemia; CML, chronic myeloid leukemia.

6 months after this event compared with patients who had not had a VT in the first 6 months.

This cohort study estimates the incidence of DVT in cancer patients by means of record linkage with a high sensitivity and specificity of the linkage procedure. Using large databases has the advantage of defining large cohorts; 66329 cancer patients having all types of cancer, with 2149 cases of VT. Tumors of the bone, ovary, brain, and pancreas had the highest risk of thrombosis which is consistent with other studies, as well as the high risk in the presence of distant metastases [2,3,7,11]. Although we found that tumors of the bone, ovary, brain, and pancreas have the highest risk of thrombosis, most cases of VT were observed in patients with cancer of the breast, prostate, lung and colon as these types of cancer are more prevalent and have a longer survival time (Table 2).

Tumors of the ovary, pancreas, lung, stomach, and hematological malignancies had a high incidence of VT in the year before the cancer diagnosis. This is consistent with a recently published study [12].

At the Cancer Registry, initial therapy is registered without dates of start and finish of treatment. Therefore, an accurate association between therapy and VT over time could not be estimated. Therapy not given as initial therapy but later during the course of the disease and therefore not registered would cause an underestimation of the risk. Therapy given after the event of VT would cause an overestimation of the risk. However, the estimated RRs in our study are still consistent with other studies $[1,3,11,13]$. Surgery was not associated with an increased risk in contrast with other studies. Although we corrected for distant metastases, patients not undergoing surgery might have had cancer in a more advanced stage of disease, which would lead to an underestimation of the RR. In a subgroup of patients we found that patients not undergoing surgery have slightly more often lymphogenic metastases (data not shown). An increased risk of recurrent thrombosis was also found before, although incidences in these studies were higher [14-16].

There are several drawbacks which can lead to uncertainty in the estimated incidences. First, the incident cases of VT are not completely captured in the database of the anticoagulation clinics. In our study, in one of the anticoagulation clinics in the earlier years, registration of indications was not complete and we may have missed approximately $5 \%$ of the VT events. Furthermore, patients with DVT who have not been treated with oral anticoagulants are not registered in the anticoagulation clinics, for example, the patients who died within 1 or 2 weeks after the VT incident. The percentage of short-term case fatality rate of VT events in cancer patients is reported to be approximately $12-25 \%[17,18]$. 
Table 3 Effect of therapy on risk of venous thrombosis

\begin{tabular}{|c|c|c|c|}
\hline & VTE & No VTE & Relative risk $^{\dagger}(95 \% \mathrm{CI})$ \\
\hline No metastases, total & 332 & 30226 & \\
\hline Metastases, total & 168 & 8013 & \\
\hline \multicolumn{4}{|l|}{ Chemotherapy* } \\
\hline No metastases & 69 & 3438 & $2.0(1.6-2.7)$ \\
\hline Metastases & 61 & 1520 & $2.3(1.7-3.1)$ \\
\hline \multicolumn{4}{|l|}{ Radiotherapy* } \\
\hline No metastases & 105 & 11115 & $0.8(0.6-1.0)$ \\
\hline Metastases & 15 & 1026 & $0.7(0.4-1.1)$ \\
\hline \multicolumn{4}{|l|}{ Surgery* } \\
\hline No metastases & 254 & 22781 & $1.1(0.8-1.4)$ \\
\hline Metastases & 35 & 1730 & $0.9(0.6-1.3)$ \\
\hline \multicolumn{4}{|l|}{ Hormone therapy* } \\
\hline \multicolumn{4}{|l|}{ Breast cancer } \\
\hline No metastases ${ }^{1}$ & 79 & 1386 & $1.8(1.4-2.3)$ \\
\hline Metastases $^{2}$ & 13 & 150 & $1.3(0.7-2.6)$ \\
\hline \multicolumn{4}{|l|}{ Prostate cancer } \\
\hline No metastases ${ }^{3}$ & 21 & 618 & $1.2(0.7-1.9)$ \\
\hline Metastases $^{4}$ & 20 & 491 & $1.2(0.6-2.2)$ \\
\hline
\end{tabular}

*Reference group are the patients without chemotherapy, radiotherapy, surgery or hormone therapy.

${ }^{\dagger}$ Adjusted for age and sex.

${ }^{1}$ Of 7711 women without metastases without venous thrombotic event (VTE) and 277 women without metastases with VTE.

${ }^{2}$ Of 527 women with metastases without VTE and 37 women with metastases with VTE.

${ }^{3}$ Of 2760 men without metastases without VTE and 83 men without metastases with VTE.

${ }^{4}$ Of 1104 men with metastases without VTE and 41 men with metastases with VTE.

Recently, we have studied the same question for lung and pancreas cancer for hospital-based cohorts of patients with these diagnoses [3,4]. In both studies the cumulative incidences in the first 6 months after cancer diagnosis (74.3/1000, 95\% CI: $68.3-80.3$ for pancreatic cancer and 39.1/1000, 95\% CI: $22.7-55.5$ for lung cancer) were higher than the incidence found in this study $(22.7 / 1000,95 \% \mathrm{CI}$ : 16.6-31.0 for pancreatic cancer and 13.8/1000, 95\% CI: 11.6-16.4 for lung cancer). For $50 \%$ of the patients with pancreatic cancer and $10 \%$ of lung cancer patients, the information was obtained from the medical records and was not available in the anticoagulation clinic. These patients were not treated with oral anticoagulants because of a poor prognosis.

Secondly, there is the uncertainty of the linkage procedure. To estimate the magnitude of this uncertainty, we performed a validation study. Our cohort was defined as the patients registered at the Comprehensive Cancer Center West. The linkage of the Cancer Registry and the Anticoagulation Clinic database in the validation study is performed in an opposite way, as described. We assume that the sensitivity and specificity of our procedure in the main study will be the same as that observed in the validation study $-94.0 \%$ and $99.1 \%$, respectively.

We observed an incomplete coverage of the Cancer Registry in the validation study of $98.2 \%$, but for the main study we are interested in the coverage of the anticoagulation clinics. In the
Netherlands, all patients who use oral anticoagulants are registered and treated in the anticoagulation clinic in their area, so we expect the coverage to be high, as from the Cancer Registry.

In the validation study, two $(1.8 \%)$ of the cancer patients changed address from outside the area of the Cancer Registry to inside the area of the Cancer Registry. For the main study, we were interested in the percentage of cancer patients registered at the Cancer Registry, moving out of the area of the anticoagulation clinic between their diagnosis of cancer and a diagnosis of DVT because this will cause an underestimation of the VT incidence. Presumably, this percentage will be comparable with the $1.8 \%$ observed in the validation study.

Primary prophylaxis of VT would be beneficial if the incidence of major bleeding while undergoing prophylactic treatment, would be at least less than the incidence of VT while not undergoing prophylactic treatment. This is a precious balance, as patients with cancer are at increased risk of hemorrhage while treated with anticoagulants. For cancer patients, incidences of major bleeding of $4-7.5 \%$ in 6 months during treatment with low-molecular-weight heparins or oral anticoagulants have been reported $[14,19]$. The overall incidences of VT in the first half year in our study do not exceed this risk of major bleeding. However, for patients with distant metastases at diagnosis the incidence of VT exceeds the incidence of 40/1000/6 months for testicular, uterus, and pancreatic cancer. For these types of cancer, prophylactic treatment might be beneficial. Knowing that our risk estimates are underestimations, especially for cancers with a poor prognosis, we believe that patients with other types of cancer also could benefit from prophylactic anticoagulant treatment. Prophylactic anticoagulant treatment for these patients should be studied in clinical trials.

\section{Acknowledgements}

The authors wish to thank H. Frensen, MD for his help with retrieving data from the Anticoagulation Clinic of the Hague. We thank Ms K. van der Kooy, and Mr L. Paardekooper of the Comprehensive Cancer Center West, Leiden, for their help and advice during the linkage procedure. This study was supported by the Dutch Cancer Foundation (RUL 99/1992).

\section{References}

1 Heit JA, Silverstein MD, Mohr DN, Petterson TM, O'Fallon WM, Melton LJ III. Risk factors for deep vein thrombosis and pulmonary embolism: a population-based case-control study. Arch Intern Med 2000; 160: 809-15.

2 Blom JW, Doggen CJ, Osanto S, Rosendaal FR. Malignancies, prothrombotic mutations, and the risk of venous thrombosis. JAMA 2005; 293: 715-22.

3 Blom JW, Osanto S, Rosendaal FR. The risk of a venous thrombotic event in lung cancer patients: higher risk for adenocarcinoma than squamous cell carcinoma. $J$ Thromb Haemost 2004; 2: 1760-5. 
4 Blom JW, Osanto S, Rosendaal FR. High risk of venous thrombosis in patients with pancreatic cancer. A cohort study of 202 patients. Eur $J$ Cancer 2005; DOI: 10.1016/j.ejca.2005.09.013.

5 Sörensen HT, Mellemkjær L, Steffensen FH, Olsen JH, Nielsen GL. The risk of a diagnosis of cancer after primary deep venous thrombosis or pulmonary embolism. $N$ Engl J Med 1998; 338: 1169-73.

6 Baron JA, Gridley G, Weiderpass E, Nyren O, Linet M. Venous thromboembolism and cancer. Lancet 1998; 351: 1077-80.

7 Levitan N, Dowlati A, Remick SC, Tahsildar HI, Sivinski LD, Beyth R, Rimm AA. Rates of initial and recurrent thromboembolic disease among patients with malignancy versus those without malignancy. Risk analysis using Medicare claims data. Medicine (Baltimore) 1999; 78: 285-91.

8 Schouten LJ, Straatman H, Kiemeney LA, Gimbrere CH, Verbeek AL. The capture-recapture method for estimation of cancer registry completeness: a useful tool? Int J Epidemiol 1994; 23: 1111-6.

9 Coebergh JW, Janssen-Heijnen ML, Louwman WJ, Voogd AC. Cancer Incidence, Care and Survival in the South of the Netherlands 1955-1999: A Report of the Eindhoven Cancer Registry with Crossborder Implications. Eindhoven: Comprehensive Cancer Centre South (IKZ), 2001.

10 Oger E. Incidence of venous thromboembolism: a community-based study in Western France. EPI-GETBP Study Group. Groupe d'Etude de la Thrombose de Bretagne Occidentale. Thromb Haemost 2000; 83: 657-60.

11 Otten HM, Mathijssen J, ten Cate H, Soesan M, Inghels M, Richel DJ, Prins MH. Symptomatic venous thromboembolism in cancer patients treated with chemotherapy: an underestimated phenomenon. Arch Intern Med 2004; 164: 190-4.

12 White RH, Chew HK, Zhou H, Parikh-Patel A, Harris D, Harvey D, Wun T. Incidence of venous thromboembolism in the year before the diagnosis of cancer in 528,693 adults. Arch Intern Med 2005; 165: 1782-7.
13 Deitcher SR, Gomes MP. The risk of venous thromboembolic disease associated with adjuvant hormone therapy for breast carcinoma: a systematic review. Cancer 2004; 101: 439-49.

14 Prandoni P, Lensing AW, Piccioli A, Bernardi E, Simioni P, Girolami B, Marchiori A, Sabbion P, Prins MH, Noventa F, Girolami A. Recurrent venous thromboembolism and bleeding complications during anticoagulant treatment in patients with cancer and venous thrombosis. Blood 2002; 100: 3484-8.

15 Palareti G, Legnani C, Lee A, Manotti C, Hirsh J, D'Angelo A, Pengo V, Moia M, Coccheri S. A comparison of the safety and efficacy of oral anticoagulation for the treatment of venous thromboembolic disease in patients with or without malignancy. Thromb Haemost 2000; 84: 80510.

16 Hutten BA, Prins MH, Gent M, Ginsberg J, Tijssen JG, Büller HR. Incidence of recurrent thromboembolic and bleeding complications among patients with venous thromboembolism in relation to both malignancy and achieved international normalized ratio: a retrospective analysis. J Clin Oncol 2000; 18: 3078-83.

17 Anderson FA Jr, Wheeler HB, Goldberg RJ, Hosmer DW, Patwardhan NA, Jovanovic B, Forcier A, Dalen JE. A populationbased perspective of the hospital incidence and case-fatality rates of deep vein thrombosis and pulmonary embolism. The Worcester DVT Study. Arch Intern Med 1991; 151: 933-8.

18 Cushman M, Tsai AW, White RH, Heckbert SR, Rosamond WD, Enright P, Folsom AR. Deep vein thrombosis and pulmonary embolism in two cohorts: the longitudinal investigation of thromboembolism etiology. Am J Med 2004; 117: 19-25.

19 Lee AY, Levine MN, Baker RI, Bowden C, Kakkar AK, Prins M, Rickles FR, Julian JA, Haley S, Kovacs MJ, Gent M. Low-molecularweight heparin versus a coumarin for the prevention of recurrent venous thromboembolism in patients with cancer. N Engl J Med 2003; 349: 146-53. 